\title{
HIV/AIDS-RELATED KNOWLEDGE, SEXUAL PRACTICES AND PREDICTORS OF CONDOM USE AMONG LONG-DISTANCE TRUCK DRIVERS IN NIGERIA
}

\author{
P N Aniebue, $M B B S, F W A C P$ \\ Department of Community Medicine, University of Nigeria Teaching Hospital, Enugu, Nigeria \\ U U Aniebue, $M B$ BS, FWACS \\ Department of Obstetrics and Gynaecology, University of Nigeria Teaching Hospital
}

\begin{abstract}
Background. Long-distance truck drivers (LDTDs) are exposed to high-risk sexual behaviour because of the nature of their work and are at high risk for HIV acquisition. Assessing their sexual practices and condom use is an important step in HIV/AIDS prevention in this target group.
\end{abstract}

Objective. To determine HIV/AIDS-related knowledge, sexual practices and predictors of condom use among Nigerian LDTDs.

Design, setting, subjects. A cross-sectional survey of 116 LDTDs in Enugu, Nigeria, was carried out using pretested structured questionnaires.

Results. The 116 respondents ranged in age from 21 to 69 years with a mean of 40.5 years; 95.7\% were aware of HIV/AIDS, $88.8 \%$ identified unprotected sexual intercourse as a mode of transmission, and $78.4 \%$ knew that use of a condom during sexual intercourse protects against HIV/AIDS transmission. Ninety-eight drivers $(84.5 \%)$ engaged in extramarital sexual relationships and $42.9 \%$ had multiple sexual partners. Of the drivers $43.1 \%$ had used condoms at some stage and $28.6 \%$ used them consistently. Reasons for non-use were mainly unavailability, sexual dissatisfaction and religious convictions. Age, marital status and educational status were significant predictors of condom use among sexually active LDTDs.

Conclusion. Condom use among LDTDs is low despite their high-risk sexual behaviour. Promotion campaigns to improve the general acceptability of condoms are recommended. Improved distribution of condoms at the stations where the drivers stop would improve accessibility and use.

The United Nations AIDS Report (2005, cited by Ibrahim') showed that HIV is continuing to spread to an alarming extent all over the world, particularly Africa. By the end of 2006 it was estimated that there were 2.99 million Nigerians living with HIV/AIDS, and heterosexual transmission accounted for nearly $80 \%$ of cases of HIV infection. ${ }^{2}$ Long-distance truck drivers (LDTDs) are known to engage in high-risk sexual behaviour. Long periods away from home and family results in high levels of engagement with commercial sex workers, so drivers are exposed to HIV and other sexually transmitted infections (STIs).

The correct and consistent use of condoms is an important component in the prevention of STIs, including HIV infection, and is reported to be the most reliable method of prevention other than abstinence. ${ }^{3}$ Although knowledge about condoms is relatively high and in- creasing in many African countries, including Nigeria, there has as yet been no commensurate increase in their use. ${ }^{3}$

The aim of this study was to determine HIV/AIDS-related knowledge, sexual practices and predictors of condom use among LDTDs in Nigeria. The findings may inform policy makers on how to design effective programmes to promote condom use in this high-risk group.

\section{MATERIALS AND METHODS}

A cross-sectional survey of 130 male LDTDs was carried out at three major truck depots in Enugu, south-eastern Nigeria. The minimum sample size was calculated using the formula $p \times q /(S E)^{2}$, where $p=$ prevalence, $q=100-p$ and $S E=$ sampling error tolerated. ${ }^{4}$ Using a 
prevalence of $65.6 \%$ from a previous study 5 and a sampling error of $5 \%$ the minimum sample size required was calculated as 93 , but a total of 130 drivers were studied to accommodate attrition.

The drivers were consecutively recruited into the study over a 3-month period. The objectives of the study were explained to them and confidentiality was assured by non-inclusion of identifying characteristics in the questionnaire that was used for data collection. Verbal consent was then received from each driver before recruitment into the study.

The pre-tested structured questionnaire was administered to the drivers by medical students specially trained for the survey. Information obtained from the questionnaires were the socio-demographic characteristics of the drivers, their knowledge of HIV/AIDS, sexual practices and condom use, and factors influencing condom use. Data analysis was carried out with Epi Info version 2002 computer software. The chi-square test was used for testing statistical significance. A pvalue $<0.05$ was considered to indicate statistical significance.

\section{RESULTS}

Of a total of 130 questionnaires distributed 116 were correctly filled in, giving a response rate of $89.2 \%$. The drivers ranged in age from 21 to 69 years. Twenty-seven (23.3\%) were single, 88 (75.9\%) married and 1 (0.9\%) widowed. They were predominantly Christians and the majority had secondary or primary education (Table I). Of the drivers $95.7 \%$ were aware of HIV/AIDS, and the major source of information on this was the media (41.9\%). Other sources included health talks (25.2\%),

\section{TABLE I. SOCIO-DEMOGRAPHIC CHARACTERISTICS OF} 116 LDTDs STUDIED

$\begin{array}{lr}\text { Age (yrs) } & N \\ 21-30 & 29 \\ 31-40 & 37 \\ 41-50 & 31 \\ 51-60 & 12 \\ >60 & 7\end{array}$

Marital status

Single

27

Married

88

Widowed

1

Religion

Christianity

87

Islam

27

Others

1

Educational level

No formal education

8

Primary education

Secondary

Tertiary

49

48

11 friends (21.3\%) and church (11.6\%). Knowledge of modes of transmission and prevention of HIV/AIDS is shown in Table II. One hundred and three drivers $(88.8 \%)$ knew that HIV could be transmitted through unprotected sexual intercourse, and 91 (78.4\%) identified condom use as one of the modes of prevention of transmission.

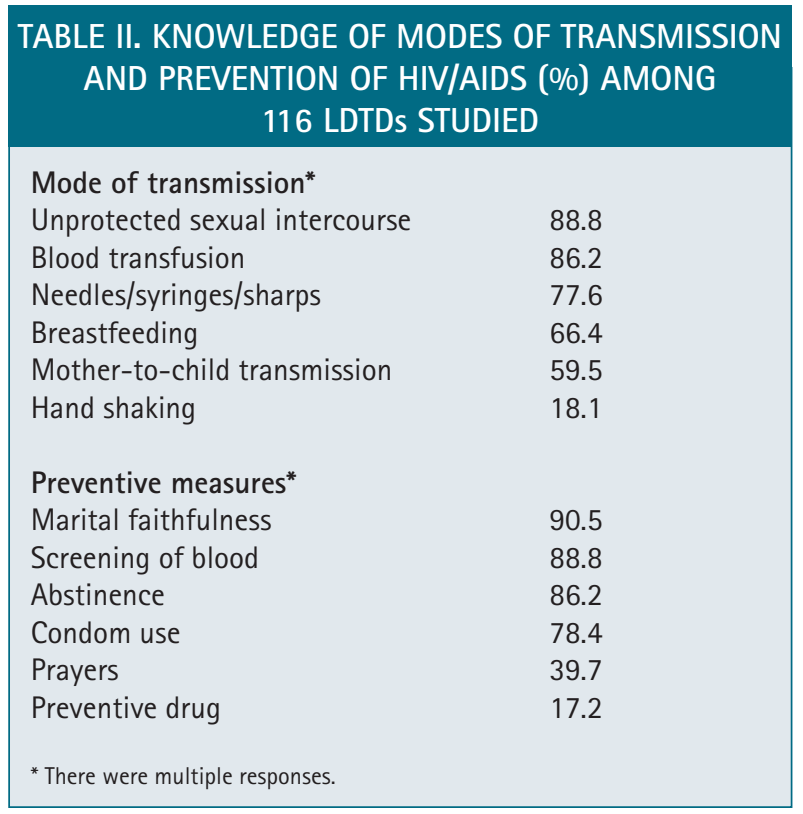

Ninety-eight drivers (84.5\%) engaged in extramarital sexual relationships. Forty-two of these (42.9\%) had multiple sexual partners, while one (0.01\%) was bisexual. During the 6 months prior to the study 92 drivers (79.3\%) had engaged in extramarital sex.

Fifty drivers (43.1\%) had ever used condoms during extramarital sex, $38(38.8 \%)$ had used condoms in their last extramarital sexual relationship, and $28.6 \%$ consistently used condoms when engaged in extramarital sexual relationships. The majority of those who used condoms (71.2\%) got them from a pharmacy shop, other sources being sexual partners ( 2 cases) and a health facility (1). The main reasons for not using a condom were unavailability (16 cases, 30.8\%), perception of reduced sexual satisfaction $(15,28.8 \%)$, religion $(8,15.4 \%)$, embarrassment about buying condoms $(5,9.4 \%)$, itching $(5,9.4 \%)$ and fear that the condom would burst or tear $(3,5.8 \%)$. Use of condoms during extramarital sex had been suggested by $82.0 \%$ of the drivers and by $18.0 \%$ of their partners. Table III shows the relationship between condom use in the last extramarital sexual relationship and socio-demographic characteristics of the drivers. Condom use was significantly higher among drivers with higher levels of education, unmarried drivers and drivers in the younger age group.

\section{DISCUSSION}

Condoms are a key preventive strategy as rates of HIV and other sexually transmitted infections continue to increase. When used correctly and consistently male 


\section{TABLE III. RELATIONSHIP BETWEEN SOCIO-DEMOGRAPHIC VARIABLES AND USE OF CONDOM IN LAST}

EXTRA-MARITAL SEX (73 SUBJECTS)

\begin{tabular}{|c|c|c|c|}
\hline & Used condom & Did not use condom & $p$-value \\
\hline \multicolumn{4}{|l|}{ Age (yrs) } \\
\hline $21-30$ & $9(39.1 \%)$ & $14(60.9 \%)$ & \multirow{4}{*}{$\begin{array}{l}\chi^{2}=12.82 \\
\text { df } 3 \\
p<0.001\end{array}$} \\
\hline $31-40$ & $20(60.6 \%)$ & $13(39.4 \%)$ & \\
\hline $41-50$ & 7 (26.9\%) & $19(73.1 \%)$ & \\
\hline$>50$ & $2(12.5 \%)$ & $14(87.5 \%)$ & \\
\hline \multicolumn{4}{|l|}{ Marital status } \\
\hline Single/widowed & $15(60.0 \%)$ & $10(40.0 \%)$ & \multirow{2}{*}{$\begin{array}{l}\chi^{2}=6.37 \\
\text { df } 1, p=0.01\end{array}$} \\
\hline Married & $23(31.5 \%)$ & $50(68.5 \%)$ & \\
\hline \multicolumn{4}{|l|}{ Educational status } \\
\hline No formal/primary & $14(26.9 \%)$ & $38(73.1 \%)$ & \multirow{3}{*}{$\begin{array}{l}\chi^{2}=6.57 \\
\text { df 2, } \\
p=0.037\end{array}$} \\
\hline Secondary & $20(52.6 \%)$ & $18(47.4 \%)$ & \\
\hline Tertiary & $4(50.0 \%)$ & 4 (50.0\%) & \\
\hline
\end{tabular}

condoms can provide as much as $94 \%$ reduction in the risk of HIV transmission. ${ }^{6}$ Many drivers in this study were aware of HIV/AIDS, the media being their major source of information. This finding is consistent with a previous report on HIV/AIDS knowledge among LDTDs. ${ }^{7}$ The majority of the drivers correctly identified unprotected sex as a mode of transmission of HIV/AIDS and the consistent use of condoms as a preventive measure.

Despite this high level of knowledge about HIV/AIDS many of the drivers (84.5\%) still engaged in risk-taking behaviour, including extramarital sex. However, only $43.1 \%$ had ever used condoms and only $28.6 \%$ used condoms consistently during sex with casual partners. Ekanem et al. ${ }^{5}$ reported that of intra-city bus drivers in Lagos, western Nigeria, 65.6\% had ever used condoms and $11.6 \%$ consistently used them. In contrast, Podhista et $a l^{8}$ reported a high level (58.5\%) of consistent condom use in a study of LDTDs in Thailand.

The high rate of condom use in societies such as Thailand could be explained by low resistance to their use. ${ }^{9}$ Our finding of lower rates of consistent condom use may reflect the fact that in Nigeria there is an aversion to condom use, which is generally believed to be a licence to sexual promiscuity.

Use of condoms in the last episode of extramarital sex was significantly higher among drivers with secondary education or above, those who were single, and the younger age group. Other studies have corroborated this finding. ${ }^{3,10}$ It may suggest that health promotion and condom use is beginning to be effective in younger, better educated people. This should be encouraged, and appropriate media promotions of condom use utilised in order to bridge the educational divide.

The reasons given by the drivers for not using condoms included unavailability of condoms, reduced sexual satisfaction, religious beliefs, and embarrassment when buying condoms. This underscores the need for educa- tional campaigns to improve the general acceptability of condoms. " Enhanced distribution of condoms at the truck terminals might help improve their accessibility, reduce the embarrassment associated with purchase, and so increase use.

Condom use is still low among LDTDs despite their high levels of HIV-related knowledge and ongoing high-risk sexual behaviour. Enhanced distribution of condoms at truck terminals could improve access to and use of condoms in this group. There is a need for increased and sustained campaigns to educate people about condoms, using appropriate messages in the local language.

We acknowledge the help of C Okoye, S Mgbekwere and $\mathrm{E}$ Agbeyeke in distributing the questionnaires used for the survey.

\section{REFERENCES}

1. Ibrahim MTO, Opara WEK, Tanimono T. Knowledge of HIV/AIDS, infection prevention practices and accidental skin cuts in barbing saloons in Sokoto, Nigeria. Nigeria Medical Practitioner 2007; 51(6): 123-127.

2. Federal Ministry of Health, Abuja, Nigeria. National Guidelines on Prevention of Mother to Child Transmission of HIV (PMTCT). Abuja: Federal Ministry of Health, 2007: 1.

3. Sabitu K, Illiyasu Z, Baba SE. Sexual behaviour and predictors of condom use among students of a Nigerian tertiary institution. Niger J Med 2007; 16(4): 338342.

4. Akpala 0. Epidemiologic Research. A Practical Approach for the Medical and Nursing Sciences. Enugu: University of Nigeria, 1994: 64-65.

5. Ekanem EE, Afolabi BM, Nuga AO, Adebayo SB. Sexual behaviour HIV-related knowledge and condom use by intra-city commercial bus drivers and motor park attendants in Lagos, Nigeria. Afr J Reprod Health 2005; 9(1): 78-87.

6. Holmes KK, Levine $R$, Weaver $M$. Effectiveness of condoms in preventing sexually transmitted infections. Bull World Health Organ 2004; 82(45): 454-461.

7. Onwasigwe $\mathrm{CN}$, Aniebue PN, Ndu AC. Awareness and sexual behaviour of Nigerian long distance drivers. Journal of College of Medicine 2001, 6(1): 44-46.

8. Podhista C, Wawer MJ, Pramuairatama A, Kaungsukkasem U, Mcnamara R. Multiple sexual partners and condom use among long distance truck drivers in Thailand. AIDS Educ Prev 1996; 8(6): 490-498.

9. Marck J. Long-distance truck driver sexual cultures and attempts to reduce HIV risk behaviours amongst them: a review of the African and Asian literature. In: Caldwell JC, Caldwell P, Anarfi J, et al., eds. Resistances to Behavioural Change to Reduce HIV/AIDS Infection in Predominantly Heterosexual Epidemics in Third World Countries. Canberra: Health Transition Centre, National Centre for Epidemiology and Population Health, Australian National University.

10. Sunmola AM. Sexual practices, barriers to condom use and its consistent use among long distance truck drivers in Nigeria. AIDS Care 2005; 17(2): 208-221.

11. Chigbu B, Onwere S, Kamanu C, Aluka C, Feyi-Waboso PA. Awareness, acceptability and use of male condoms for contraception and prevention of sexually transmitted infection among female students in a tertiary institution in south eastern Nigeria. Niger J Clin Pract 2007; 10(3): 267-268. 